\title{
UTILIZAÇÃO DE ÁCIDOS ORGÂNICOS PARA A CONSERVAÇÃO DE CARNES: ALTERAÇÕES FÍSICAS E MICROBIOLÓGICAS
}

(Use of organic acids for meat conservation: physico and microbiological changes)

Higor Zampieri Machado ${ }^{1}$ Reis, Magali Santos Pozza ${ }^{1}$, Paula Martins Olivo ${ }^{1}$, Adriely Cristina Santos $^{1}$, Julia Jacomini ${ }^{1}$, Grasiele Scaramal Madrona ${ }^{1}$

1Universidade Estadual de Maringá, Paraná Brasil. *Corresponding author: pozzamagali@yahoo.com.br

RESUMO: Objetivou-se com esse trabalho avaliar as alterações microbiológicas e físicas da carne bovina inoculada com a bactéria Escherichia coli sob a ação de ácidos orgânicos como agentes sanitizantes. $O$ experimento foi em esquema fatorial 3X3, sendo três tratamentos e três períodos de avaliação. Os tratamentos foram: Tratamento 1: controle (utilização de água destilada), Tratamento 2: aplicação por spray, de solução contendo $1,0 \%$ de ácido lático + Escherichia coli e Tratamento 3: aplicação por spray, de solução com 1,0 \% de ácido acético + Escherichia coli. As amostras foram submetidas às avaliações de contagem de total de aeróbios mesófilos, de coliformes e físico-quimicamente, nos tempos 0,7 e 14 dias de estocagem sob refrigeração. Em relação às características físico-químicas, não foram observadas diferenças significativas $(P>0,05)$ para as interações entre os tratamentos e os tempos. Aos 14 dias de armazenamento, as amostras apresentavam menores valores AW e CRA e maiores contagens de coliformes $(P<0,05)$. $O$ ácido lático foi eficiente na redução da contagem de aeróbios mesófilos ao longo do tempo avaliado $(P<0,05)$. A adição de ácido acético resultou em menores valores de $\mathrm{pH}$ aos 14 dias. Para cor, as amostras tratadas com ácido lático estavam mais claras e com acido acético, mais vermelhas $(P<0,05)$. A utilização de ácidos orgânicos foi eficiente na redução da contagem total bacteriana $e$ proporcionou menor escurecimento das amostras..

Palavras-chave: ácido acético; ácido lático; carne bovina; Escherichia coli ; vida de prateleira

ABSTRACT: The objective of this work was to evaluate the microbiological and physical alterations of the beef inoculated with Escherichia coli bacteria under the action of organic acids as sanitizing agents. The experiment was in a 3X3 factorial scheme, with three treatments and three evaluation periods. The treatments were: Treatment 1: control (use of distilled water), Treatment 2: spray application, solution containing 1.0\% lactic acid + Escherichia coli and Treatment 3: application by spray, solution with $1.0 \%$ acetic acid + Escherichia coli. The samples were submitted to the counts of total counts of mesophilic, coliform and physico-chemically aerobic at 0,7 and 14 days of storage under refrigeration. Regarding the physical-chemical characteristics, no significant differences $(P>0.05)$ were observed for the interactions between the treatments and the times. At 14 days of storage, the samples presented lower values AW and CRA and higher counts of coliforms ( $P$ $<0.05)$. Lactic acid was efficient in reducing the count of mesophilic aerobes during the evaluated time $(\mathrm{P}<0.05)$. The addition of acetic acid resulted in lower $\mathrm{pH}$ values at 14 days. For color, the samples treated with lactic acid were lighter and with acetic acid, more red $(P<0.05)$. The use of organic acids was efficient in reducing the total bacterial count and provided less dimming of the samples

Keywords: acetic acid; bovine meat; lactic acid; Escherichia coli; shelf life 


\section{INTRODUÇÃO}

Um dos maiores desafios para a indústria de carnes é oferecer produtos macios, suculentos, com cor e sabor agradáveis, de forma que características de frescor permaneçam estáveis durante toda a sua vida de prateleira, com a maior segurança e o menor custo possível (MATHIAS et al., 2010).

Para tanto, existem diversos agentes de sanitização os quais podem ser empregados para diminuir a contaminação microbiana e que apresentam potencial de uso, dentre estes os ácidos orgânicos, os quais podem ser usados diretamente por meio da aspersão nas carcaças de animais recém-abatidos (Drehmer, 2005). O ácido acético é muito eficaz como acidificante e conservante (Lucena, 2007); o ácido lático é um dos ácidos mais abundantemente distribuídos no meio ambiente e um dos principais ácidos formados durante os processos fermentativos naturais.

No Brasil e na União Européia, a sanitização de carcaças bovinas com aspersão de ácidos orgânicos ainda não é permitida pela regulamentação de procedimentos higiênicos (Del Río et al., 2007), principalmente devido ao fato de que a utilização de ácidos orgânicos não é para ser considerada como uma ação corretiva do processo produtivo e sim como uma ação preventiva para integrar aos conjuntos de ferramentas de qualidade implantadas para garantia da qualidade do produto (Pereira et al, 2015).

Várias pesquisas têm avaliado métodos de controle microbiológico em carnes, porém com métodos diferenciados e resultados divergentes, visto que a eficiência dos ácidos orgânicos no controle dos patógenos depende do agente químico utilizado, da concentração, da forma de aplicação, da temperatura, do tempo de contato e da análise dos resultados (Vasconcelos et al., 2002). Machado et al. (2013) avaliaram carcaças no pós-abate, com a utilização de ácidos orgânicos e verificaram que o uso de água quente sob a forma de vapor e a associação com o tratamento químico resultou em melhor eficiência na redução das contaminações superficiais sem alterar os atributos físico-químicos e Vasconcellos et al. ( 2002 ) avaliando carne ovina com a inclusão de $1 \%$ de ácido acético seguida de embalagem a vácuo, verificaram sua eficiência em controlar bactérias mesófilas, bolores, leveduras e coliformes, sendo ineficiente no controle de Salmonella. Soares et al (2016) avaliando de carne bovina tratada com aditivos (ácido lático a $1 \%$ e lactato de sódio a $3 \%$ ) de forma combinada, não constataram crescimento de coliformes a $35^{\circ}$ e $45^{\circ} \mathrm{C}$.

Dentre as bactérias contaminantes em carnes, os coliformes podem ser avaliados para constatar a eficiência de tratamentos em alimentos. Por tratar-se de uma bactéria de habitat originalmente fecal, a Escherichia coli é a mais conhecida e a mais facilmente diferenciada dos gêneros não entéricos (JAY, 2005).

Devido

a divergências encontradas na literatura, na utilização de ácidos orgânicos como agentes sanitizantes, concentração a ser testada, forma de aplicação, temperatura e tempo de contato, este trabalho teve como objetivo avaliar a vida de prateleira $(0,7$ e 14 dias) e mensurar as alterações microbiológicas e físico-químicas da carne bovina do corte comercial coxão mole (semimembranosus, sarotirius, adductor, gracilis e pectineus) quando inoculados com a bactéria Escherichia coli sob a ação de ácidos orgânicos na concentração de 1,0\% (acético e lático).

\section{MATERIAL E MÉTODOS}


As amostras de corte comercial, coxão mole bovino, representado pelos músculos semimembranosus, sarotirius, adductor, gracilis e pectineus foram obtidas no comércio local de Maringá e processadas no Laboratório de Alimentos e Nutrição Animal e no Laboratório de Tecnologia e Produção de Origem Animal.

Inoculou-se superficialmente as amostras de carne, de $200 \mathrm{gr}$ em média, sendo: Tratamento $1=$ tratamento controle, utilização de água destilada (sem inoculação de Escherichia coli), Tratamento 2 = contaminação superficial com $3 \mathrm{~mL}$ de Escherichia coli (E. coli) e utilização da solução de $1 \%$ de ácido lático e Tratamento $3=$ contaminação superficial com $3 \mathrm{~mL}$ de $E$. coli e aplicação de solução contendo $1 \%$ de ácido acético.

Foram realizadas as seguintes análises físicas: determinação do $\mathrm{pH}$, capacidade de retenção de água (CRA), atividade de água (AW) e avaliação da cor. Para as análises microbiológicas, avaliaram-se a presença de microorganismos aeróbios mesófilos e de coliformes fecais.

Para determinação do $\mathrm{pH}$, utilizouse um pH metro digital (Hanna) e foram aferidos os valores de $\mathrm{pH}$ nos tempos 0 , 7 e 14 dias. Para a avaliação da capacidade de retenção de água, utilizou-se o método de pressão, segundo a técnica modificada por Sierra (1973), utilizando-se uma amostra de $5 \mathrm{~g}$ de carne, cortada finamente $e$ colocando-se em cima de um peso de $2,250 \mathrm{Kg}$ durante 5 minutos, após determinou-se a diferença de peso da amostra e foi calculado em percentagem o que foi liberado para o papel filtro.

Para a atividade de água, foi utilizado 0 equipamento Novasina (LabSwift) nos tempos 0, 7 e 14 dias. $\mathrm{Na}$ avaliação da cor, utilizou-se o equipamento colorímetro Konica Minolta (CM-700d) para essa avaliação, foram realizadas seis repetições por amostra, nos tempos 0, 7 e 14 dias.

Para a inoculação inicial, um disco de Escherichia coli (New prove 0039), foi colocado em $100 \mathrm{~mL}$ de caldo nutriente a $35^{\circ} \mathrm{C}$ durante 24 horas utilizando-se banho-maria. Após 24 horas, adicionouse $3,0 \mathrm{~mL}$ do cultivo em $100 \mathrm{~mL}$ de água destilada estéril de acordo com o padrão de absorbância 0,5 da escala Mac Farland.

A técnica do suabe em zaragatoa foi utilizada para a coleta das amostras das superfícies adotando-se procedimento descrito no Manual de Métodos de Análise Microbiológica de Alimentos (Silva et al., 2007)

Foram utilizados suabes estéreis de algodão de $0,5 \mathrm{~cm}$ de diâmetro por 2 $\mathrm{cm}$ de comprimento, com haste de $12 \mathrm{~cm}$ de comprimento. Após ser umedecido em água destilada estéril, o suabe foi friccionado em seis quadrantes com área de $1 \mathrm{~cm} 2$ (utilizando-se moldes plásticos estéreis). Diluições decimais a partir da diluição 101 até 103 foram preparadas em tubos contendo $9,0 \mathrm{~mL}$ de água destilada estéril.

Para todas as amostras, em triplicata, foi realizada a contagem dos micro-organismos aeróbios mesófilos em Petrifilme AC e coliformes totais em Ágar Vermelho Violeta Bile (VRB-Himedia). Placas Petrifilm AC (3M Company, St. Paul, MN, EUA) foram inoculadas com alíquotas de $1,0 \mathrm{~mL}$ das diferentes diluições (101 a 103) das amostras seguindo as instruções do fabricante. As placas contendo ágar VRB foram semeadas na superfície nas mesmas diluições. Ambas placas foram incubadas a $35^{\circ} \mathrm{C}$ por 24 e 48 horas respectivamente.

Os resultados das contagens foram expressos em logarítmo de unidade formadora de colônia por $\mathrm{cm} 2$ ou por superfície (log UFC/cm2 ou log UFC/superfície). 
Para as análises estatísticas foi utilizado esquema fatorial $3 \times 3$, sendo três tratamentos e três tempos de avaliação. Os dados foram submetidos às análises estatísticas utilizando-se o pacote computacional SAEG (Ribeiro Júnior, 2001) desenvolvido pela Universidade Federal de Viçosa.

\section{RESULTADOS E DISCUSSÃO}

Em relação às características físicas e microbiológicas da carne bovina, não foram observadas diferenças significativas $\quad(P>0,05)$ para os tratamentos em relação aos parâmetros atividade de água, capacidade de retenção de água e contagem de coliformes. Entretanto foram observadas diferenças significativas para os tempos avaliados $(P<0,05)$.

Tabela 1- Características físicas do coxão mole submetido a tratamento utilizando ácidos orgânicos como sanitizantes.

\begin{tabular}{|c|c|c|c|}
\hline & AW & CRA $\%$ & Coliformes (UFC/ $/ \mathrm{cm}^{2)}$ \\
\hline \multicolumn{4}{|l|}{ Tempo } \\
\hline \multicolumn{4}{|l|}{ (Dias) } \\
\hline 0 & $0,99^{\mathrm{a}}$ & $87,29^{a}$ & $1,53^{b}$ \\
\hline 7 & $0,97^{\mathrm{b}}$ & $88,91^{b}$ & $1,86^{b}$ \\
\hline \multirow[t]{2}{*}{14} & $0,98^{b}$ & $90,55^{c}$ & $2,83^{a}$ \\
\hline & $y=1,032-0,049 x+$ & & $y=1,861-0,646 x+$ \\
\hline Equações & $0,0106 x^{2}$ & & $0,3236 x^{2}$ \\
\hline R2 & 0,35 & 0,33 & 0,56 \\
\hline
\end{tabular}

*AW: Atividade de água; CRA: Capacidade de retenção de água; Colif: Contagem de coliformes (E. coli).

* Em uma mesma coluna, letras iguais não diferem estatisticamente entre si $(P>0,05)$ pelo teste de Tukey

A capacidade de retenção de água aumentou com o decorrer do tempo de armazenamento (Tabela 1) contrariamente ao esperado, pois durante a estocagem refrigerada ocorre perda de água por sublimação. Perdas maiores de peso ocorrem quando há maior velocidade de ar, maior superfície de carne magra exposta, armazenamento prolongado ou temperatura mais alta (Aberle et al. 2001).

Em relação ao parâmetro de contagem de coliformes, foi observado aumento nas contagens com o decorrer do tempo de armazenamento; aos 14 dias de armazenamento foi obtido o maior valor de coliformes, podendo-se atribuir ao maior valor obtido de atividade de água (que oscilou entre 0,99 a 0,98); valor este considerado como aceitável para o desenvolvimento deste microorganismo.

Algumas pesquisas vêm destacando o efeito inibitório principalmente do ácido lático, em coliformes. Gill e Badoni (2004) constataram que o uso de solução a $4 \%$ de ácido lático em peças de carne promoveu redução de cerca de 1,5 ciclos logarítmicos de coliformes em relação às peças tratadas somente com água. Entretanto, segundo Vasconcelos (2002) o efeito inibitório dos ácidos orgânicos diminui com o período de estocagem.

Silva et al. (2001) ao aplicar solução de ácido lático a 1 e $2 \%$ em carcaças de frango constatou uma redução significativa no número mais provável de coliformes. Beyaz e Tayar (2010), ao sanitizarem carcaças ovinas com solução de ácido lático a 1\%, verificaram que este aditivo é capaz de reduzir a população de coliformes em 2,69 ciclos logarítmicos após 30 minutos e em 2,16 ciclos após 24 horas.

Para os valores observados de aeróbios mesófilos, embora não tenha sido constatada diferença entre os tratamentos, houve diferença $(P<0,05)$ para a interação entre tratamento $x$ tempo (Tabela 2).

De acordo com Silva (1999), o valor médio ideal para contagem de bactérias mesófilas em carcaças bovinas é de 1,96 log UFC $/ \mathrm{cm}^{2}$, portanto, valores superiores foram obtidos no presente estudo principalmente devido ao fato da 
inoculação com E.coli nas amostras 2 e 3.

Tabela 2- Contagem de micro-organismos aeróbios mesófilos durante 0 tempo de armazenagem das amostras

\begin{tabular}{ccccc}
\hline \multicolumn{5}{c}{ Tempo (Dias) } \\
\hline Tratamentos & 0 & 7 & 14 & $\log \Delta$ \\
\hline 1 & $2,50^{\mathrm{a}}$ & $3,05^{\mathrm{a}}$ & $3,08^{\mathrm{a}}$ & 0,58 \\
2 & $4,55^{\mathrm{ab}}$ & $4,23^{\mathrm{ab}}$ & $3,37^{\mathrm{b}}$ & $-1,18$ \\
3 & $5,79^{\mathrm{a}}$ & $5,79^{\mathrm{a}}$ & $5,31^{\mathrm{a}}$ & 0,48 \\
Equação & $\mathrm{y}=1,46263-1,36485 \mathrm{x}$ & & & \\
\hline R2 & & & & \\
\hline
\end{tabular}

${ }^{\star}$ Em uma mesma linha, letras iguais não diferem estatisticamente entre si $(P>0,05)$ pelo teste de Tukey ${ }^{\star} \mathrm{CV}: 12,96 ; \Delta \log =\log \mathrm{T} 0-\log \mathrm{T} 14$

Os resultados verificados pela ação dos tratamentos utilizando-se ácidos orgânicos sobre a contagem total de aeróbios mesófilos, durante 14 dias, evidenciam que, para o tratamento com a utilização de água (controle) e com a utilização de ácido acético não houve redução das contagens para os tempos avaliados.

As menores contagens de aeróbios mesófilos foram observadas quando utilizou-se ácido lático aos 14 dias, mostrando sua eficácia; havendo redução de 1,18 ciclos logarítmicos. Em nenhuma das amostras verificou-se contagem padrão em placas superior a 6,0 valor este considerado inaceitável para o consumo.

Para os valores médios de $\mathrm{pH}$, embora não tenha sido verificada diferença entre os tratamentos, apresentam diferença significativa $(P<0,05)$ para interação entre os tratamentos e os tempos.

Os tratamentos que utilizaram ácidos orgânicos (2 e 3), estes apresentaram pouca eficácia na redução do $\mathrm{pH}$. Esse fato pode ter ocorrido devido à concentração utilizada dos ácidos orgânicos ser relativamente baixa, ou devido ao fato de que a utilização isolada dos ácidos não se mostrarem tão eficientes como o uso de soluções contendo diferentes concentrações de ácidos orgânicos.

Tabela 3- Valores médios de $\mathrm{pH}$ no corte bovino coxão mole experimentalmente inoculados com Escherichia coli e mantidos por 14 dias de armazenamento sob refrigeração

\begin{tabular}{cccc}
\hline & \multicolumn{3}{c}{ Tempo } \\
\hline Tratamentos & 0 & 7 & 14 \\
\hline 1 & $6,04^{\mathrm{a}}$ & $6,03^{\mathrm{a}}$ & $6,12^{\mathrm{a}}$ \\
2 & $5,99^{\mathrm{a}}$ & $5,91^{\mathrm{a}}$ & $6,00^{\mathrm{a}}$ \\
3 & $5,7^{\mathrm{b}}$ & $5,43^{\mathrm{a}}$ & $5,17^{\mathrm{b}}$ \\
Equação & & $\mathrm{y}=5,58889+0,762778 \mathrm{x}-0,287222 \mathrm{x}^{2}$ \\
\hline R2 & & 0,93 &
\end{tabular}

*Em uma mesma linha, letras iguais não diferem estatisticamente entre si $(P>0,05)$ pelo teste de Tukey

Contrariamente, De Carli et al (2013) ao avaliarem carcaças de suínos aspergidas com solução de ácidos orgânicos (ácido lático, cítrico, acético e ascórbico) constataram efeito positivo para redução do $\mathrm{pH}$, embora durante os 20 dias de armazenamento os valores de $\mathrm{pH}$ mantiveram-se constantes.

$\mathrm{O} \mathrm{pH}$ durante o armazenamento é um fator que determina a qualidade da carne; verificando-se durante a vida de prateleira, aumento nos seus valores, resultando no escurecimento da carne (Aberle et al. 2001) . Segundo Terra e Brum (1988), os limites máximos de pH para consumo de carne é de 6,4 , valores acima são considerados como índice de deterioração. No presente estudo, os maiores valores para $\mathrm{pH}$ foram observados para os tratamentos controle e ácido lático, sendo obtido os valores de 6,12 e 6,0 respectivamente, aos 14 dias de armazenamento.

De acordo com a literatura, a presença de 1 a $2 \%$ de ácido acético não dissociado em carne inibem ou eliminam muitos micro-organismos presentes, podendo apenas sobreviver aos ácidos tolerantes em condições normais ou em más condições higiênicas. Esta concentração pode reduzir de forma 
significativa a presença de muitos microorganismos, principalmente em produtos refrigerados (Lima, 2003). No presente estudo, o menor valor de $\mathrm{pH}$ foi obtido para o tratamento contendo $1 \%$ de ácido acético $(5,17)$.

Para os parâmetros de cor, $L^{*} e b^{*}$ houve interação significativa entre os tratamentos e os tempos avaliados $(P<0,05)$.

Tabela 4- Parâmetros $L^{*}$ e $b^{*}$ de amostras tratadas com água e ácidos orgânicos

\begin{tabular}{ccc}
\hline & $\mathrm{L}$ & $\mathrm{b}$ \\
\hline Tratamentos & & \\
\hline 1 & $39,41^{\mathrm{b}}$ & $14,64^{\mathrm{b}}$ \\
2 & $41,36^{\mathrm{a}}$ & $14,87^{\mathrm{b}}$ \\
3 & $40,92^{\mathrm{ab}}$ & $15,97^{\mathrm{a}}$ \\
\hline
\end{tabular}

${ }^{\star}$ Em uma mesma coluna, letras iguais não diferem estatisticamente entre si $(P>0,05)$ pelo teste de Tukey

A cor é o atributo que mais influencia a compra de carne bovina pelos consumidores (Velho et al. 2009). Segundo Rossato et al (2010), as coordenadas fundamentais de cor $L^{*}, a^{*}$ e $b^{*}$ na carne retratam a luminosidade, que é influenciada pela quantidade de água na superfície da peça, consequência da capacidade de retenção de água (Purchas, 1990) portanto, quanto mais escuras as amostras maior capacidade de retenção de água. No presente estudo não houve diferença para CRA entre os tratamentos, somente o aumento do seu valor durante 0 armazenamento refletindo o escurecimento das amostras durante o período avaliado.

$$
\text { Muchenjeaet al. }
$$

descreveram que em bovinos, as médias de luminosidade (L) variam entre 33,2 e 41,0 . Os valores médios obtidos nesse estudo, para o tratamento controle foram de 39,41 para luminosidade. Os resultados evidenciam diferença significativa $(P>0,05)$ para interação entre tratamentos e tempos. Foi observado no tratamento 2 (ácido lático) maior valor médio para o parâmetro $L^{*}$ 41,36, evidenciando assim, amostras mais claras, embora, quando avaliadas no decorrer do tempo, as amostras foram tornando-se mais escuras.

$\mathrm{O}$ teor de vermelho, que reflete a quantidade de pigmento vermelho presente na mioglobina e no citocromo $\mathrm{C}$ (Hedrick et al. 1994); e o teor de amarelo, que é associado a composição de carotenóides (Priolo et al. 2001).

Acredita-se que a sanitização das carcaças com soluções diluídas a 1 e $2 \%$ de ácidos orgânicos não afetam as propriedades sensoriais da carne. Porém quando cortes cárneos são imersos em soluções ácidas, os efeitos observados são mais prejudiciais, resultando em descoloração, alterações de sabor e exsudação (Smulders \& Greer, 1998).

Muchenjeaet al. (2009) obtiveram em seu estudo, valores médios de cor amarela, entre 6,1 e 11,3. No presente estudo, para a variável $b$, houve interação entre os tratamentos e o tempos, verificando-se que o tratamento que apresentou maior valor de $b^{*}$ foi 0 tratamento 3 (ácido acético) obtendo-se o valor de 15,97; valores um pouco acima dos verificados pelo autor citado, havendo maior intensidade da cor amarela.

$\mathrm{Na}$ Tabela 5 foram observadas diferenças significativas $(P<0,05)$ nos parâmetros $L^{*}$ e $b^{*}$ nos tempos avaliados.

As alterações na cor da carne podem ser relacionadas ao frescor e também ao tempo de exposição do corte ao ambiente, pois à medida que ocorre o envelhecimento, há escurecimento da superfície que se torna progressivamente escura ou acinzentada, podendo apresentar irisdescência ou colorações esverdeada e azulada, pela ação de microorganismos

Tabela 5- Parâmetros $L^{*}$ e b*da cor do músculo 


\begin{tabular}{lcc}
\multicolumn{3}{l}{ de coxão mole nos tempos avaliados } \\
\hline \multicolumn{3}{l}{$\mathrm{L}$} \\
\hline Tempo (Dias) \\
\hline 0 & $42,65^{\mathrm{a}}$ & $18,52^{\mathrm{a}}$ \\
7 & $39,88^{\mathrm{b}}$ & $14,10^{\mathrm{b}}$ \\
& & $12,87^{\mathrm{c}}$ \\
14 & $39,16^{\mathrm{b}}$ & \\
Equações & $\mathrm{y}=47,512-0,059 \mathrm{x}+1,041 \mathrm{x}^{2}$ & $\mathrm{y}=26,109-0,0918 \mathrm{x}+1,590 \mathrm{x}^{2}$ \\
\hline R2 & 0,99 & 0,99
\end{tabular}

${ }^{*}$ Em uma mesma coluna, letras iguais não diferem estatisticamente entre si $(P>0,05)$ pelo teste de Tukey

Foram observadas diferenças nos valores médios $(\mathrm{P}<0,05)$ para os parâmetros $L^{*}$ e $b^{*}$ para os tempos avaliados; sendo observado no dia 0 , os maiores valores.

Para o parâmetro $\mathrm{a}^{*}$ (Tabela 6), foram observadas diferenças significativas $(P<0,05)$ para interação entre tratamentos e tempos.

Tabela 6- Parâmetro $a^{*}$ e interação entre tratamentos e tempos para as amostras de carne experimentalmente inoculadas por 14 dias

\begin{tabular}{ccrc}
\hline \multicolumn{4}{c}{ Tempo (Dias) } \\
\hline Tratamentos & 0 & 7 & 14 \\
\hline 1 & $18,86^{\mathrm{a}}$ & $9,76^{\mathrm{b}}$ & $10,12^{\mathrm{a}}$ \\
2 & $19,62^{\mathrm{a}}$ & $9,35^{\mathrm{b}}$ & $9,90^{\mathrm{a}}$ \\
3 & $19,47^{\mathrm{a}}$ & $14,54^{\mathrm{a}}$ & $10,59^{\mathrm{a}}$ \\
\multirow{2}{*}{ Equação } & \multicolumn{3}{c}{$\mathrm{y}=22,6760-0,04545 \mathrm{x}$} \\
\hline R2 & \multicolumn{3}{c}{0,82}
\end{tabular}

${ }^{*}$ Em uma mesma coluna, letras iguais não diferem estatisticamente entre si $(P>0,05)$ pelo teste de Tukey

Para a análise da cor, a variável a* indica coloração vermelha, verificandose diferença significativa $(P<0,05)$ para as interações entre tratamentos e tempos. O tratamento 3 (utilização de ácido acético) apresentou maiores valores médios para $a^{*}$, indicando assim, uma coloração mais avermelhada, ou seja, possivelmente mais apreciada pelos consumidores.

A cor da carne reflete a quantidade e o estado químico do seu principal pigmento, a mioglobina. Os pigmentos da carne podem apresentar alterações de cor (do vermelho brilhante ao marrom) associadas a fatores extrínsecos como pressões de oxigênio, temperatura, sal e bactérias aeróbias (Roça, 2010). As concentrações de mioglobina podem variar em diferentes cortes de carne bovina (músculos), proporcionando diferença da cor vermelha (Lima Júnior et al., 2013).

Segundo Farias et al. (2011) variação nos teores de $a^{*}$ podem ser explicadas em função da baixa atividade respiratória mitocondrial da carne, no inicio do armazenamento, o que resulta no aumento do oxigênio na superfície do corte, originando a oximioglobina de cor vermelha brilhante. Como a variável $a^{*}$ está relacionada também ao conteúdo de mioglobina no músculo, com o passar do tempo, essa pode ser extravasada junto com o exsudato da carne, diminuindo a intensidade da cor vermelha.

A cor vermelha da carne também pode adquirir tons de verde, marrom ou cinza, devidos à produção, por bactérias, de $\mathrm{H}_{2} \mathrm{~S}$, compostos oxidantes e peróxidos, por exemplo (Alcantara et al. 2012).

Pereira et al (2015) não observaram diferença na cor da carne sanitizada com ácidos orgânicos, embora os autores tenham constatado nas amostras sanitizadas, coloração vermelha mais intensa que a amostra testemunha.

\section{CONCLUSÃO}

As amostras tratadas com ácido acético possuíam maior intensidade da cor vermelha aos 7 dias e menores valores de $\mathrm{pH}$ aos 14 dias. A utilização de ácido lático, além de também proporcionar menor escurecimento das amostras, aos 14 dias reduziu a contagem bacteriana, ambos apresentando potencial de uso como sanitizantes para amostras contaminadas com Escherichia coli. 


\section{REFERENCES}

ABERLE, E. D.; FORREST, J. C.; GERRARD, D. E. et al. Principles of meat science. $4^{\underline{a}}$ ed. Kendall/Hunt, lowa, 354p. 2001.

ALCANTARA, M.,; MORAIS, I.C.L.; MATTOS, C. et al. Principais Microrganismos envolvidos na deterioração das características sensoriais de derivados cárneos. Revista Brasileira de Higiene e Sanidade Animal, v.6, n.1, 2012.

BEYAZ, D.; TAYAR, M. The Effect of Lactic Acid Spray Application on the Microbiological Quality of Sheep Carcasses. Journal of Animal and Veterinary Advances, v. 9, n. 13, p. 1858-1863, 2010.

DE CARLI, E.M., TERRA, N.N.; FRIES, L.L.M. et al. Descontaminação de cortes suínos com ácidos orgânicos comerciais, solução salina acidificada e luz ultravioleta. Semina: Ciências Agrárias, Londrina, v. 34, n. 3, p. 11951204, maio/jun. 2013.

DEL RÍO, E., PANIZO-MORÁN, M., PRIETO, M. et al. Effect of various chemical decontamination treatments on natural microflora and sensory characteristics of poultry. International Journal Food Microbiology. v 115, p.268-280. 2007.
DREHMER, A.M.F. Quebra de peso das carcaças suínas e estudo da vida de prateleira da carne. 2005. $115 f$. Dissertação (Mestrado em Ciências e Tecnologia dos Alimentos) - Curso de Pós Graduação em Ciência e Tecnologia dos Alimentos - Universidade Federal de Santa Maria, RS, 2005.

FARIAS, D.S.; GIANGARELI, B.L.; GODRIM, J.S. et al. Estabilidade da cor da carne de bovinos armazenada sob refrigeração. In: XXI CONGRESSO BRASILEIRO DE ZOOTECNIA, Universidade Federal de Alagoas. Maceió, 23 a 27 de maio de 2011. Anais. INOVAÇÕES TECNOLÓGICAS E MERCADO CONSUMIDOR. 2011.

FRANCO, B.D.G.M.; LANDGRAF, M. Microbiologia de Alimentos. São Paulo: Atheneu, 2004. 128p.

GILL, C.O.; BADONI, M. Effects of peroxyacetic acid, acidified sodium chlorite or lactic acid solutions on the microflora of chilled beef carcasses. International Journal of Food Microbiology, v. 91, n. 1, p. 43-50, 2004.

HEDRICK, H.B. Principles of meat science. 3.ed. Dubuque: Kendall/Hunt Publishing, 354p, 1994.

INSTITUTO ADOLFO LUTZ. Métodos físico-químicos para análise de 
alimentos. Coordenadores ZENEBON, O.; PASCUET, N. S.; TIGLEA, P. São Paulo: Instituto Adolfo Lutz. p. 1020. 2008.

\section{JAY, J. M. Microbiologia Moderna de}

Los Alimentos. 3. Ed., Zaragoza: Acribia, 804 p .2005.

LIMA JÚNIOR, D.M.; RANGEL, A.H.N.; URBANO, S.A. et al. Oxidação lipídica e qualidade de carne ovina. Acta veterinária Brasilica, v. 7, n. 1p. 14-28, 2013.

\section{LIMA, J. ICMSF, Ecologia microbiano} de los alimentos. Glossário de Carlos Vander Becke, ácido acético em alimentos. Zaragoza: Acribia, v. 1, 2003.

\section{LUCENA, R. F. Isolamento e} caracterização de Aeromonas em carcaças suínas. 2007. 98 f. Dissertação (Mestrado em Biotecnologia)-Curso de Pós-graduação em Biotecnologia, Instituto de Biotecnologia, Caxias do Sul, 2007.

Machado, A. R.; Gouvela, F.C.; AlmeidA , L.C. et al. Avaliação microbiologica e fisicoqumica de pernis suínos tratados com ácidos orgânicos e/ou vapor no controle da contaminação superficial por Salmonella Typhimurium. Ciência Animal Brasileira, v. 14, n3, 2013.

MATHIAS, S.P.; ROSENTHAL, A.; GASPAR, A. et al. Alterações oxidativas (cor e lipídios) em presunto de peru tratado por Alta Pressão Hidrostática (APH). Ciência Tecnologia de Alimentos, Campinas, 30(4): 852- 857, out.-dez. 2010.

MUCHENJEA, V.; DZAMAC, B.K.; CHIMONYOA, M. Some biochemical aspects pertaining to beef eating quality and consumer health: a review. Food Chemistry, v.112, p.279-289, 2009.

PEREIRA, T.L. Avaliação da ação sanitizante do ácido peracético em peças de carne bovina. 2015. 70 f. Dissertação (Mestrado em Engenharia de Produção) - Universidade Tecnológica Federal do Paraná, Ponta Grossa, 2015.

RIBEIRO JÚNIOR, J.I. Análises estatísticas no SAEG. Viçosa, MG: UFV, 2001.

ROSSATO, L.V.; BRESSAN, M.C; RODRIGUES, E.C. et al. Parâmetros físico-químicos e perfil de ácidos graxos da carne de bovinos Angus e Nelore terminados em pastagem. Revista Brasileira de Zootecnia, vol.39, $n^{\circ} 5$, 2010.

PRIOLO, A.; MICOL, D.; AGABRIEL, J. Effects of grass feeding systems on ruminant meatcolour and flavour: a review. Animal Research, v.50, p.185200, 2001. 
PURCHAS, R.W. An assessment of the role of $\mathrm{pH}$ differences in determining the relative tenderness of meat from bulls and steers. Meat Science, v.27, p.120140, 1990.

ROÇA, R.O. Composição química da carne. Material didático. Laboratório de Tecnologia dos Produtos de Origem Animal. Fazenda Experimental Lageado, UNESP - Campus de Botucatu, 2010.

ROÇA, R.O. Refrigeração. Material didático. Laboratório de Tecnologia dos Produtos de Origem Animal. Fazenda Experimental Lageado, UNESP Campus de Botucatu, 2011.

SILVA, J.A.; SOARES, F.L.; COSTA, L.E. Sanitização de carcaças de frango com soluções de ácidos orgânicos comerciais e suco de limão. Revista Tecnologia de Carnes, Campinas, v. 23, p. 19-26, 2001.

SILVA, J.A. Sanitização da carne com ácidos orgânicos. Parte 1. Higiene Alimentar, v.13, n.60, p.55-62, 1999.

SILVA, N., JUNQUEIRA, V.C.A., SILVEIRA, N.F.A. Manual de Métodos de Analise Microbiológica de Alimentos. São Paulo, SP: Logomarca Varela, 3를 edição, 2007

SIERRA, I. Producción de cordero joven y pesado en la Raza Aragoneza.
Zaragoza: I.E.P.G.E, n. 18, 1973.

TERRA, N.N.; BRUM, M.A. Carne e seus Derivados: Técnicas de Controle de Qualidade. São Paulo: Nobel, p.119, 1988.

SOARES, K.M.P., SOUZA, L.B. \& SILVA, J.B.A. Coliformes totais e termotolerantes em bifes de carne bovina tratados com ácido lático e lactato de sódio. Revista Brasileira de Ciência Veterinária, 23, 196-199. 2016.

SMULDERS, F.J.; GREER, G.G. Integrating microbial decontamination with organic acids in HACCP programmes for muscle foods: Prospects and controversies. International Journal of Food Microbiology, 44 (3), p. 149-169. 1998.

VASCONCELOS, E.C., ZAPATA, J.F.F., FIGUEIREDO E.A. et al. A microbiota da carcaça e da carne ovina tratada com ácido acético, embalada a vácuo e maturada por 48 dias. Ciência Tecnologia Alimentar., Campinas, v. 22, n. 3, 2002.

VELHO, J.P. Disposição dos consumidores porto-alegrenses à compra de carne bovina com certificação. Revista Brasileira de Zootecnia. v. 38. 2009. 